\title{
Synthesis and Mossbauer studies of mesoporous $\gamma-\mathrm{Fe}_{2} \mathrm{O}_{3}$
}

\author{
V.O. Kotsyubynsky ${ }^{1 *}$, V.V. MoKLyAK ${ }^{2}$, A.B. Hrubiak ${ }^{1}$ \\ ${ }^{1}$ Vasyl Stefanyk Precarpathian National University, 57 Shevchenko Str., Ivano-Frankivsk, 76025, Ukraine \\ ${ }^{2}$ Institute of Metal Physics, National Academy of Science, 36 Acad. Vernadsky Boulevard., Kyiv, 03680, Ukraine
}

\begin{abstract}
A method of synthesis of mesoporous $\gamma-\mathrm{Fe}_{2} \mathrm{O}_{3}$ by thermal decomposition of iron citrate has been proposed. Investigations of the crystalline and magnetic structure of obtained materials were done. Nanodispersed maghemite $\left(\gamma-\mathrm{Fe}_{2} \mathrm{O}_{3}\right)$ with the sizes of coherent scattering regions of about $4-7 \mathrm{~nm}$ consisted of one phase only after gel sintering at 200,250 and $300{ }^{\circ} \mathrm{C}$. The particles of synthesized materials were both in magnetically ordered, and superparamagnetic states, and they formed a grid-like mesoporous structure. The influence of magnetic dipole interparticle interaction on the parameters of Mossbauer spectra was observed. A phenomenological model of the differences between nanodispersed $\gamma-\mathrm{Fe}_{2} \mathrm{O}_{3}$ magnetic microstructures obtained after annealing at different temperatures was presented.
\end{abstract}

Keywords: $\gamma-\mathrm{Fe}_{2} \mathrm{O}_{3}$; mesoporous structure; Mossbauer spectroscopy; superparamagnetic properties

(C) Wroclaw University of Technology.

\section{Introduction}

Improving of methods of nanodispersed iron oxides synthesis opens new possibilities for obtaining novel functional materials. Nanostructured iron oxides have numerous applications such as memory devices [1], magnetic resonance imaging [2], drug delivery [3], biological markers [4], electrochemical power sources [5] and photocatalysts [6]. The investigation of nanodispersed iron oxides, formation of their crystal and magnetic structures and the effect of synthesis conditions on the material phase composition and morphology is an important and hot topic.

\section{Experimental details}

Nanodispersed maghemite, $\gamma-\mathrm{Fe}_{2} \mathrm{O}_{3}$, was synthesized by a sol-gel method.

The colloidal solution of $\mathrm{Fe}\left(\mathrm{NO}_{3}\right)_{3} \cdot 9 \mathrm{H}_{2} \mathrm{O}$ and $\mathrm{C}_{6} \mathrm{H}_{8} \mathrm{O}_{7} \cdot \mathrm{H}_{2} \mathrm{O}$ (molar ratio $1: 1$ ) was aged at $60{ }^{\circ} \mathrm{C}$ for $12-15$ days. The sedimentated iron citrate hydrate was dried in the air at $50-60{ }^{\circ} \mathrm{C}$. The obtained xerogel was sintered at temperatures of 100, $150,200,250,300{ }^{\circ} \mathrm{C}$ during 1 hour. The prepared

*E-mail: v_ kotsuybynsky@mail.ru samples were investigated by XRD $(\mathrm{Cu} \mathrm{K} \alpha$ radiation), Mossbauer spectroscopy (calibration relative to $\alpha-\mathrm{Fe}$ ) and scanning electron microscopy (SEM).

Sintering at temperatures of 100 and $150{ }^{\circ} \mathrm{C}$ did not change the amorphous state of the material but after sintering at temperatures of 200, 250 and $300{ }^{\circ} \mathrm{C} \gamma-\mathrm{Fe}_{2} \mathrm{O}_{3}$ with the lattice parameter $\mathrm{a}=$ $0.83388 \pm 0.00015 \mathrm{~nm}$ was the only crystalline phase in the material (Fig. 1).

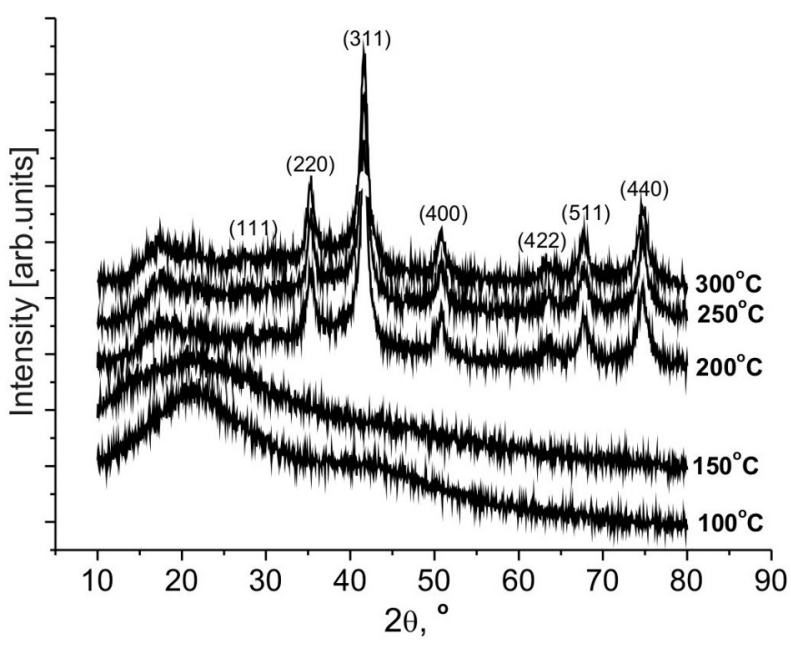

Fig. 1. X-ray diffraction patterns of $\gamma-\mathrm{Fe}_{2} \mathrm{O}_{3}$ samples obtained at the different sintering temperatures. 
Halos observed in the XRD patterns (Fig. 1) are caused by the presence of the X-ray amorphous component in the samples. Average sizes of X-ray coherent scattering areas calculated by the Scherrer equation for a sample sintered at a temperature of $200{ }^{\circ} \mathrm{C}$ and for samples after sintering at 250 and $300{ }^{\circ} \mathrm{C}$ are about $5 \pm 1 \mathrm{~nm}$ and $6 \pm 1 \mathrm{~nm}$, respectively.

Accordingly to the scanning electron microscopy data, all materials obtained after sintering for 1 hour at 200, 250 and $300{ }^{\circ} \mathrm{C}$ are characterized by porous structure as a result of evaporation of metal-organic precursor decomposition products (Fig. 2).

Mossbauer spectroscopy gave independent information about phase composition, magnetic microstructure and iron ions valence. At the conditions of partially disordered magnetic system (samples sintered at 200,250 and $300{ }^{\circ} \mathrm{C}$ ) it was impossible to establish the contribution of each partial component to Mossbauer spectra. So, we have used the idea about the formation of continuous distribution of hyperfine magnetic field at the ${ }^{57} \mathrm{Fe}$ nucleus in the $\gamma-\mathrm{Fe}_{2} \mathrm{O}_{3}$ structure, based on the method described by J. Hesse et al. [7].

\section{Results and discussion}

Mossbauer spectra of the synthesized materials with the individual deconvoluted components are presented in the Fig. 3 and 4. The parameters of hyperfine interactions (hyperfine magnetic field induction $\mathrm{B}_{h f}$, isomer shift $\delta$, quadrupole splitting $\Delta$, line width $\omega$, integral intensity $S$ ) determined from the numerical fitting of the spectra are listed in Table 1.

Sintering at the $100{ }^{\circ} \mathrm{C}$ did not cause any substantial changes in the crystalline and magnetic microstructure of the original sample. The values of isomer shift ( $\delta=0.41 \mathrm{~mm} / \mathrm{s}$ ) and quadrupole splitting $(\Delta=0.54-0.56 \mathrm{~mm} / \mathrm{s})$ for a doublet component of the original and sintered at $100{ }^{\circ} \mathrm{C}$ samples (Fig. 3) are different from the data for iron citrate [8] and are close to the results in the report [9], where the superparamagnetic (SP) particles of $\gamma-\mathrm{Fe}_{2} \mathrm{O}_{3}$ with the diameter $<10 \mathrm{~nm}$ in polymeric matrix have been studied.

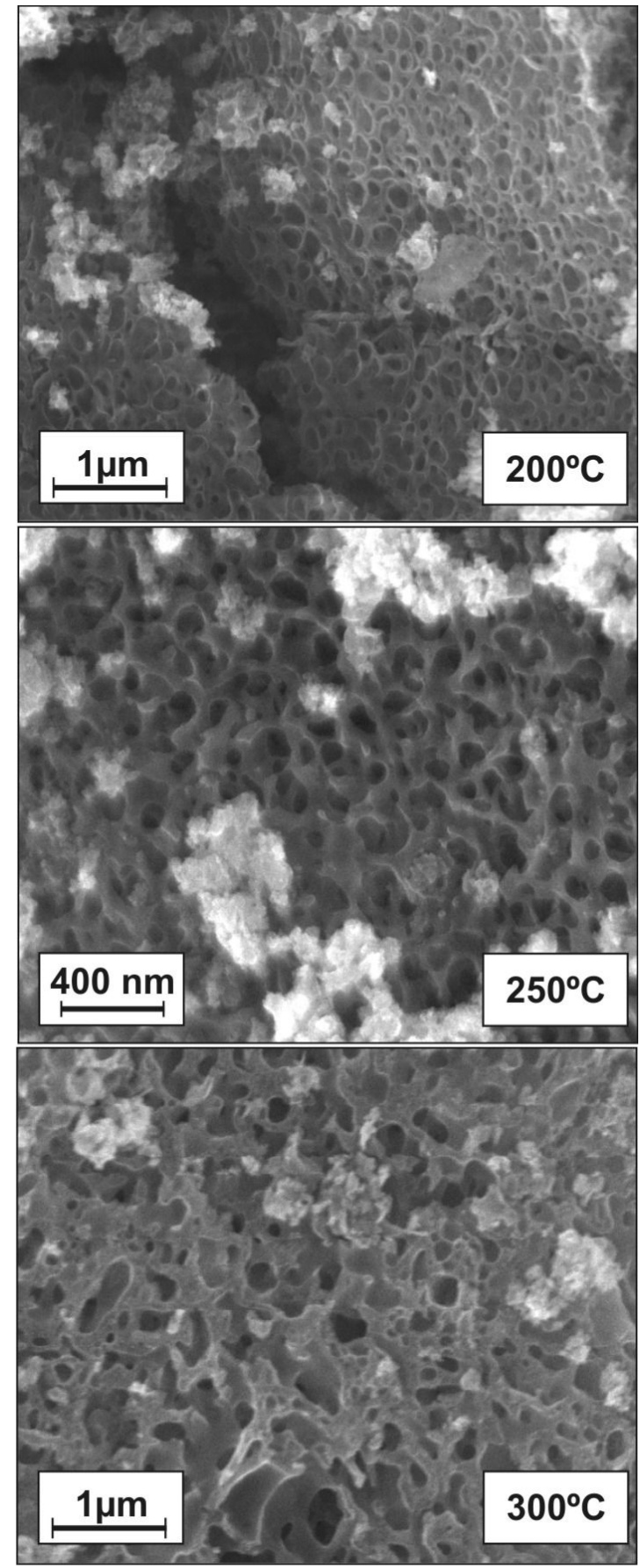

Fig. 2. SEM images of $\gamma-\mathrm{Fe}_{2} \mathrm{O}_{3}$ samples obtained at different sintering temperatures.

Sintering at $150{ }^{\circ} \mathrm{C}$ caused an increase of $\delta$ and $\Delta$ values. The spectrum is a superposition of the three partial components (Fig. 4). Two doublet components have the isomer shift 0.53 and $0.52 \mathrm{~mm} / \mathrm{s}$ and quadrupole splitting 0.80 
Table 1. Parameters of Hyperfine Interactions for Synthesized Materials.

\begin{tabular}{cccccc}
\hline Sample & $\begin{array}{c}B_{h f} \\
(\mathrm{~T})\end{array}$ & $\begin{array}{c}\delta \\
(\mathrm{mm} / \mathrm{s})\end{array}$ & $\begin{array}{c}\Delta \\
(\mathrm{mm} / \mathrm{s})\end{array}$ & $\begin{array}{c}\omega \\
(\mathrm{mm} / \mathrm{s})\end{array}$ & $\begin{array}{c}S \\
(\%)\end{array}$ \\
\hline \hline Original xerogel & - & 0.41 & 0.55 & 0.35 & 100 \\
\hline $100{ }^{\circ} \mathrm{C}$ & - & 0.41 & 0.56 & 0.37 & 100 \\
\hline \multirow{3}{*}{$150{ }^{\circ} \mathrm{C}$} & - & 0.53 & 0.80 & 0.34 & 49.3 \\
& - & 0.52 & 1.32 & 0.40 & 43.8 \\
& - & 1.37 & 2.19 & 0.30 & 6.9 \\
\hline \multirow{3}{*}{$200{ }^{\circ} \mathrm{C}$} & - & 0.48 & 0.80 & 0.45 & 27.7 \\
& - & 0.48 & 1.32 & 0.45 & 15.1 \\
& - & 0.46 & -0.08 & 3.60 & 21.6 \\
& $42.0^{*}$ & 0.44 & -0.03 & 0.43 & 35.6 \\
\hline \multirow{2}{*}{$250{ }^{\circ} \mathrm{C} 1$ hour } & - & 0.47 & 0.73 & 0.43 & 18.0 \\
& - & 0.46 & 1.25 & 0.49 & 13.6 \\
& - & 0.53 & 0.01 & 4.20 & 24.2 \\
& $44.0^{*}$ & 0.45 & -0.01 & 0.37 & 44.1 \\
\hline \multirow{3}{*}{$300{ }^{\circ} \mathrm{C}$} & - & 0.35 & 0.74 & 0.38 & 19.7 \\
& - & 0.32 & 1.20 & 0.63 & 80.2 \\
\hline & - & 0.48 & 0.74 & 0.40 & 36.9 \\
& $41.2^{*}$ & 0.47 & 1.24 & 0.51 & 43.0 \\
& & -0.09 & 0.36 & 20.1 \\
\hline
\end{tabular}

*for materials, obtained after sintering at 200, 250 and $300{ }^{\circ} \mathrm{C}$ the average most probable values of hyperfine magnetic field induction $B_{h f}$ are presented.

and $1.32 \mathrm{~mm} / \mathrm{s}$, respectively, and correspond to resonance absorption by the nucleus of tetrahedral coordinated ions $\mathrm{Fe}^{3+}$ in the high-spin state.

The values of quadrupole splitting depend on the lattice deformation under the Laplace pressure. The third doublet with $1.37 \mathrm{~mm} / \mathrm{s}$ and $2.19 \mathrm{~mm} / \mathrm{s}$ is formed as a result of resonance absorption by nucleus of $\mathrm{Fe}^{2+}$ ions.

Magnetically ordered components of Mossbauer spectra for materials obtained after sintering at 200 and $250{ }^{\circ} \mathrm{C}$ are 35.6 and $44.1 \%$ of integral intensity, respectively, which reflects the particles enlarging with temperature increase. The function of hyperfine field distribution is characterized by one maximum at about $49 \mathrm{~T}$. Paramagnetic parts of the spectra contain two components which respond to the resonance absorption by ${ }^{57} \mathrm{Fe}$ nucleus in the superficial and inner regions of mesoporous $\gamma$ - $\mathrm{Fe}_{2} \mathrm{O}_{3} 3 \mathrm{D}$-grid.

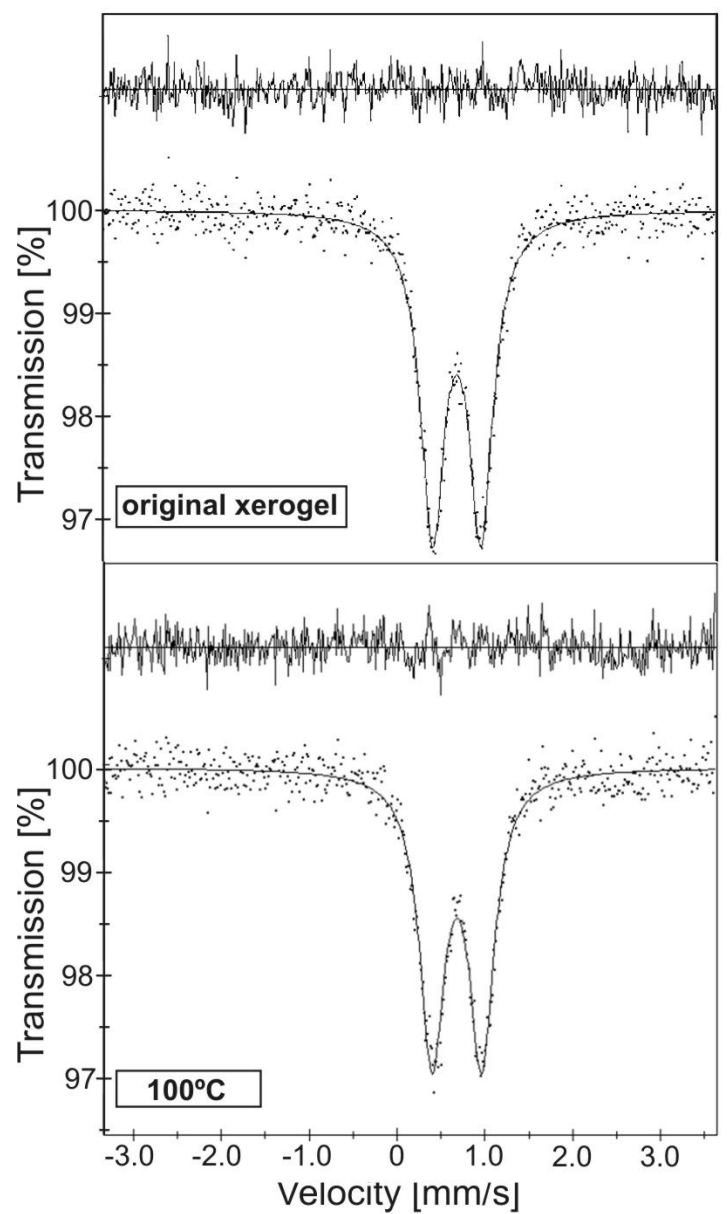

Fig. 3. Mossbauer spectra of original xerogel before and after sintering at $100{ }^{\circ} \mathrm{C}$ during 1 hour.

The tendency to decreasing $\delta$ and $\Delta$ results from particles (domain) enlarging and increasing of covalence degree of $\mathrm{Fe}-\mathrm{O}$ bonds. The presence of the doublet with broadened lines is the characteristic peculiarity of these spectra. Similar spectra were observed for iron oxide nanoclusters obtained by thermal decomposition of ferric oxalate [10].

In the spectrum of a sample sintered at the $300{ }^{\circ} \mathrm{C}$ the wide doublet component is absent and the magnetically ordered part does not exceed $20 \%$ of integral intensity with preserving of two component composition of the central doublet.

The values of $\delta$ and $\Delta$ for the materials obtained by sintering at 200,250 and $300^{\circ} \mathrm{C}$ are lower in comparison to the data for microcrystalline 
$\gamma-\mathrm{Fe}_{2} \mathrm{O}_{3}$ [11]. It is caused by attenuation of the superexchange interaction as a result of an increase of the amount of ${ }^{57} \mathrm{Fe}$ nucleus with destroyed bonds.

The changes of magnetic microstructures in the synthesized material are caused by size effects and SP phenomena. The obtained materials are the systems of monodomain clusters with fluctuated magnetic moments. This fluctuations cause the broadening of spectral components and disappearance of magnetic hyperfine structure at a certain value of material magnetic anisotropy, which determines the relaxation time $\tau_{r}$ of a particle magnetic moment. Relaxation time is calculated as $\tau_{r}=$ $\tau_{0} \exp \left(\frac{K V}{k T}\right)$, where $\tau_{0} \approx 10^{-9}-10^{-10} \mathrm{~s}$, V: particle volume, $\mathrm{K}$ : constant of anisotropy, T: temperature. For a particle with certain values $\mathrm{K}$ and $\mathrm{V}$ the conversion from superparamagnetic to magnetically ordered state occurs at a blocking temperature $\left(\mathrm{T}_{B}\right)$. For a system of magnetic nanoparticles the variant of magnetic interaction energy (sum of exchange and dipole energies) between two neighboring particles dominating up to anisotropy energy is possible [12]. An influence of exchange effects on the macroscopic magnetic characteristics of materials is reflected in the appearance of magnetic nanomaterials properties similar to the characteristics of spin glass, the appearance of blocking temperature shift, disagreement of structural and magnetic data. Transitions are stimulated by defects, cluster interactions, strains on the interphase boundaries, which is typical of nanoclusters system. Oscillation blocking takes place at the effective temperature $T_{e f}=T_{B}+T *$ where the temperature shift $T *$ reflects the influence of dipole-dipole interaction and determines the value of its energy.

Wide doublet component in the spectra of the samples obtained by sintering at 200 and $250{ }^{\circ} \mathrm{C}$ represents an intermediate stage between magnetically ordered and SP states of a particle in the case of strong dipole-dipole interaction. These systems show SP properties at temperatures higher than $T_{B}$. At temperatures lower than $T_{B}$ these systems resemble spin glass and their spectra contain broad doublet. This component is a result of resonance absorption by the ${ }^{57} \mathrm{Fe}$ nucleus, for which the hyperfine field has the value between zero, and satu-

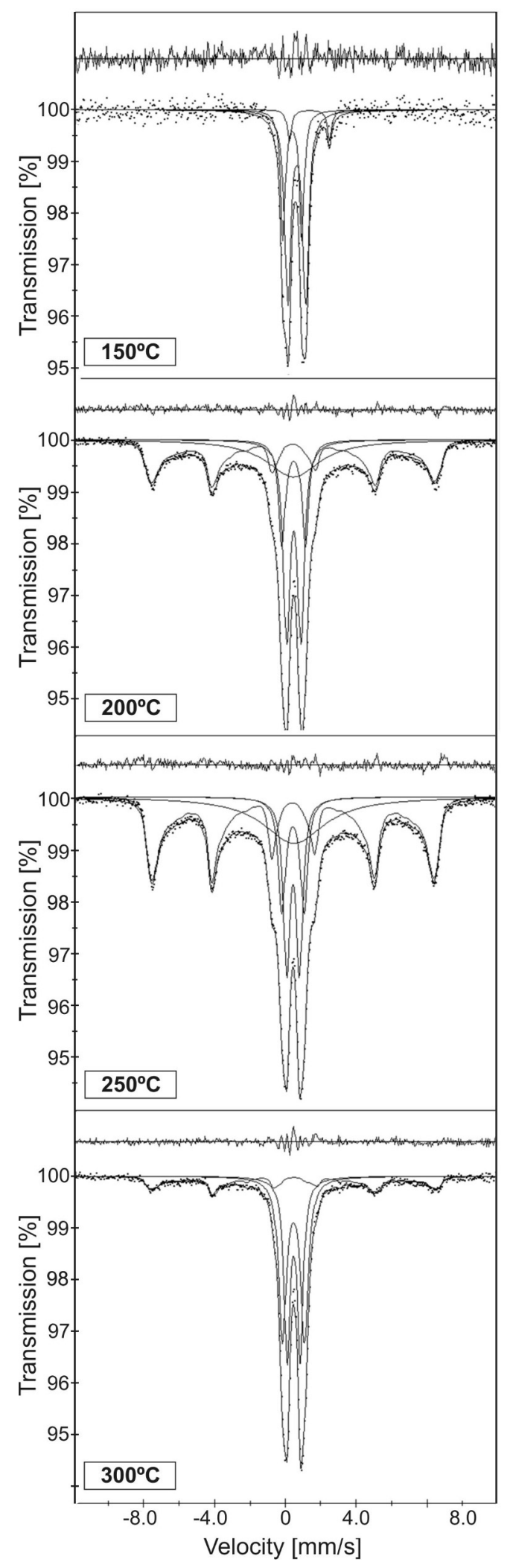

Fig. 4. Mossbauer spectra of materials obtained by sintering at $150,200,250$ and $300^{\circ} \mathrm{C}$ during 1 hour. 
ration level. Thermal fluctuation of magnetic moment of particles takes place but the "temporary hangings up" are possible. So, the transition to SP state is not observed although the energy of thermal fluctuations exceeds the anisotropy energy [13].

The constant of magnetic anisotropy for the particles of $\gamma-\mathrm{Fe}_{2} \mathrm{O}_{3}(6.5 \mathrm{~nm})$ is $1.2 \cdot 10^{6} \mathrm{~J} / \mathrm{m}^{3}$ [14]. Another value of $\kappa\left((2.1 \pm 0.3) \cdot 10^{5} \mathrm{~J} / \mathrm{m}^{3}\right)$ has been reported for $\gamma-\mathrm{Fe}_{2} \mathrm{O}_{3}$ particle with a size of $10 \mathrm{~nm}$ [15]. In this case for the value of $\kappa=5 \cdot 10^{5} \mathrm{~J} / \mathrm{m}^{3}$ particles less than $4.2-4.8 \mathrm{~nm}$ at room temperature are superparamagnetic, which corresponds to XRD data.

For sintering at $250{ }^{\circ} \mathrm{C}$ an increase of treatment time to 3 hours caused disappearance of magnetic ordered component in Mossbauer spectrum (Fig. 5b). Accordingly to XRD data (Fig. 5a) this sample is amorphous. So, structural and magnetic properties of the obtained materials depend on thermal treatment conditions.

After comparative analysis of the hyperfine interactions parameters for the doublet components determined for the systems sintered at $250{ }^{\circ} \mathrm{C}$ during 1 and 3 hours we can make a conclusion about an increase of $\mathrm{Fe}-\mathrm{O}$ bonding covalence degree without changes in magnetic neighborhood.

\section{Conclusions}

To sum up the experimental data we can build a phenomenological model. Amorphous regions of $\gamma-\mathrm{Fe}_{2} \mathrm{O}_{3}$ phase are nucleated as a result of thermal destruction of original xerogel. After sintering at $200{ }^{\circ} \mathrm{C}$ they partially crystallize and form a mesoporous $3 \mathrm{D}$-grid due to $\mathrm{NO}_{2}, \mathrm{CO}_{2}$ and $\mathrm{H}_{2} \mathrm{O}$ evaporation. Particle size distribution causes coexistence of magnetic ordered and superparamagnetic states of different parts of the grid. An increase in sintering temperature (up to 250 and $300{ }^{\circ} \mathrm{C}$ ) leads to intensification of these processes with an increase of pore sizes and chain thickness. Interparticle dipoledipole magnetic interaction is observed for the materials obtained by xerogel sintering at 200 and $250{ }^{\circ} \mathrm{C}$. Sintering at $250{ }^{\circ} \mathrm{C}$ for 3 hours leads to full dehydration of the material with the bridges destroyed between particles and fragmentation of
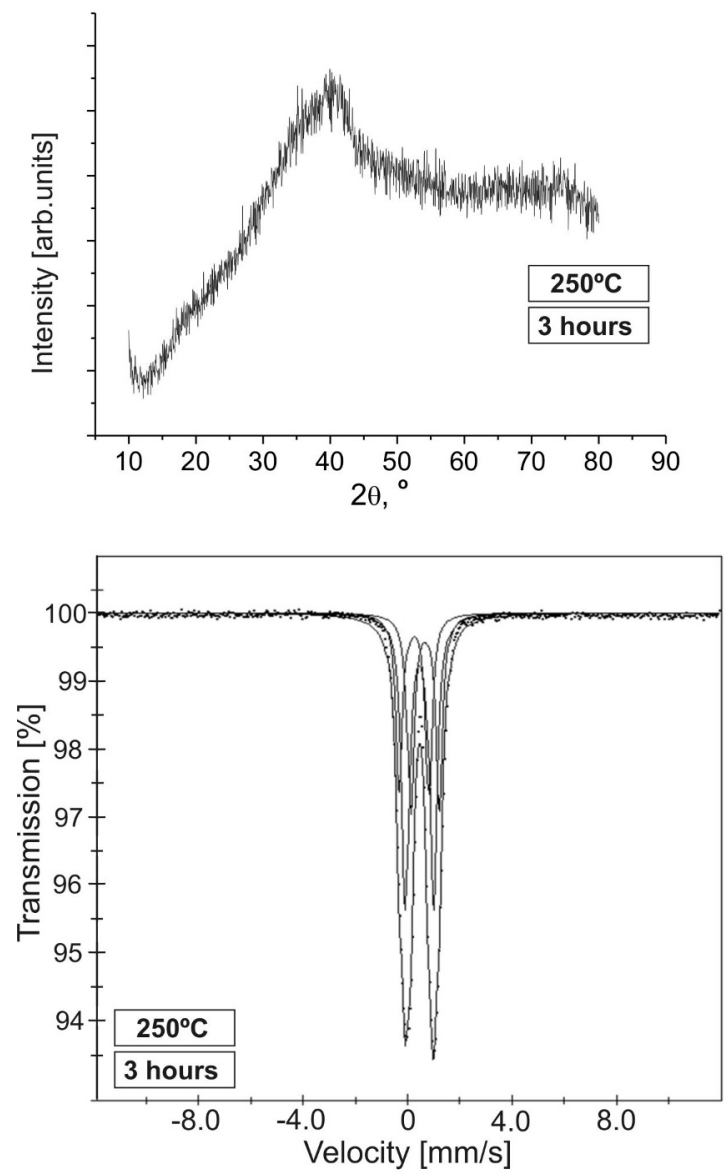

Fig. 5. XRD pattern (a) and Mossbauer spectrum (b) of material obtained by sintering at $250{ }^{\circ} \mathrm{C}$ during 3 hours.

the grid structure due to formation of paramagnetic amorphous product.

\section{References}

[1] Akinaga H., Shima H., P. IEEE, 98 (2010), 2237.

[2] Taboada E., Solanas R., Rodriguez E., Weissleder R., RoIG A., Adv. Funct. Mater, 19 (2009), 2319.

[3] CaO S.-W., ZhU Y.-J., Ma M.-Y., Li L., Zhang L., J. Phys. Chem. C, 112 (2008), 1851.

[4] Liong M., Lu J., Kovochich M., Xia T., Ruehm S.G., Nel A.E., TAmanoi F., ZinK J.I., ACS Nano, 2 (2008), 889.

[5] Aricò A. S., Bruce P., Scrosati B., TArascon J.M., SCHALKWIJK VAN W., Nat. Mater., 4 (2005), 366.

[6] Apte S.K., Naik S.D., Sonawane R.S., Kale B. B., J. Am. Ceram. Soc., 90 (2007), 412.

[7] Hesse J., RüBartsch A., J. Phys. E-Sci. Instrum., 7 (1974), 526.

[8] Takashima Y., Tateishi Y., B. Chem. Soc. Jpn., 38 (1965), 1688. 
[9] Malini K.A., Anantharaman M.R., Gupta A., $B$. Mater. Sci., 27 (2004), 361.

[10] Suzdalev I.P., Maksimov Y.V., Imshennic V.K., Nanotechnologies in Russia, 1 (2006), 134.

[11] Serna C.J., Morales M.P., Surf. Coll. Science, 17 (2004), 27.

[12] Morup S., Topsoe H., Clausen B.S., Phys. Scripta, 25 (1982), 713.

[13] Dormann J.L., Bessais L., Fiorani D., J. Phys. C, 21 (1988), 2015.
[14] Coey I.M., Khalafalla D., Phys. Status Solidi A, 11 (1972), 229.

[15] Predoi D., Kuncser V., Filoti G., Rom. Rep. Phys., 56 (2004), 373.

Received 2013-12-28

Accepted 2014-05-05 